\title{
Helmut Birkhan, Pflanzen im Mittelalter. Eine
}

Kulturgeschichte

Köln/Weimar/Wien : Böhlau, 2012, 310 p., 24,90€

\section{Adeline Rege}

\section{CpenEdition}

\section{Journals}

Édition électronique

URL : http://journals.openedition.org/ifha/8167

DOI : 10.4000/ifha.8167

ISSN : 2198-8943

Éditeur

IFRA - Institut franco-allemand (sciences historiques et sociales)

Référence électronique

Adeline Rege, "Helmut Birkhan, Pflanzen im Mittelalter. Eine Kulturgeschichte », Revue de l'IFHA [En ligne], Date de recension, mis en ligne le 14 avril 2015, consulté le 22 septembre 2020. URL : http:// journals.openedition.org/ifha/8167 ; DOI : https://doi.org/10.4000/ifha.8167

Ce document a été généré automatiquement le 22 septembre 2020

(CIFHA 


\section{Helmut Birkhan, Pflanzen im Mittelalter. Eine Kulturgeschichte}

Köln/Weimar/Wien : Böhlau, 2012, 310 p., 24,90€

Adeline Rege

Helmut Birkhan, professeur émérite de langue et littérature germanique à l'Université de Vienne et spécialiste du Moyen Âge et de la civilisation celte, propose, dans cet ouvrage, une histoire culturelle des plantes au Moyen Âge. Son ambition est de mettre en lumière les relations particulières que les hommes du Moyen Âge entretenaient avec les plantes, en analysant la place et le rôle de ces dernières dans la société et dans la culture médiévales : comment les hommes du Moyen Âge considéraient-ils les plantes? Comment et de quelle manière les utilisaient-ils ? Quels effets en attendaient-ils ? Telles sont les questions qui guident cet ouvrage.

Dans l'introduction, H. Birkhan étudie la place des plantes dans le système culturel médiéval. Il présente également ses principales sources : les œuvres d'Albert le Grand, de Hildegarde de Bingen, ainsi que de Konrad von Megenberg, dont le Buch der Natur fut le premier ouvrage de sciences naturelles en langue allemande.

Le premier chapitre aborde les plantes du point de vue de leur utilité économique. Le Moyen Âge faisait la distinction entre les plantes inutiles (les mauvaises herbes), et les plantes utiles. H. Birkhan dresse un inventaire de celles-ci, qu'il classe en catégories (fruits, légumes, céréales...), en précisant leur mode de consommation ou d'exploitation, et leurs qualités, nutritionnelles par exemple. L'usage « magique » des plantes, d'après le titre du chapitre, mais en réalité médical, fait l'objet du chapitre suivant. Birkhan montre que, dans la culture médiévale, chaque plante possède une vertu thérapeutique selon le projet de Dieu, et qu'il faut la recueillir et l'utiliser de la bonne manière. L'auteur construit ensuite un inventaire des plantes médicinales présentes chez Hildegarde de Bingen, en indiquant, pour chacune, son nom moderne et ses vertus. Le jardin, qui réunit plantes d'agrément et médicinales, fait le lien avec le chapitre suivant, qui lui est consacré.

Ce sont les ordres monastiques qui ont forgé la culture du jardin telle que nous la connaissons. Le jardin d'Éden incarne le modèle du jardin médiéval : il comprend une 
fontaine ou un bassin, de l'herbe fraîche, des arbres, des fleurs, des animaux. Le jardin clos est aussi l'expression d'une distinction sociale, puisque tout un chacun n'est pas autorisé à y pénétrer ni à participer aux activités qui y sont organisées (repas, tournois, jeux...). Par la clôture, le jardin se distingue de l'environnement quotidien, et se trouve lié à l'intime, voire à l'amour. Le jardin est ainsi le cadre de l'action du Roman de la rose de Guillaume de Lorris et Jean de Meung.

Le chapitre suivant traite des plantes, en tant que symboles du pouvoir. Le lys et la rose furent des motifs héraldiques répandus dans toute l'Europe. H. Birkhan s'attarde sur la fleur de lys, symbole de la foi, de la chevalerie et de la sagesse, et symbole héraldique des rois de France à partir de Robert le Pieux. Dans les deux derniers chapitres, H. Birkhan s'intéresse à la symbolique sacrée et profane des plantes. Les plantes sacrées d'origine biblique, telles que le figuier, l'olivier, ou le blé, incarnent la terre promise et l'abondance. Dans la symbolique chrétienne, les plantes sont surtout associées à la Vierge Marie. Par sa beauté, la Vierge est comparée à un arbre; par sa fertilité, à un jardin. De même qu'elles permettent de chanter l'amour mystique, les plantes servent à célébrer la beauté féminine et à chanter l'amour terrestre, dans l'imaginaire profane.

Grâce à cette analyse, complétée par une bibliographie ainsi que par un index des plantes, H. Birkhan offre une introduction utile et riche à l'histoire des plantes au Moyen Âge. Si le lecteur novice trouvera de nombreuses informations intéressantes dans cet ouvrage, le spécialiste sera sans doute déçu, et regrettera que le corpus de sources soit très réduit: Konrad von Megenberg et Hildegarde de Bingen ne sauraient être utilisés de manière quasi exclusive, et ils auraient été utilement complétés par des chroniques, des livres de cuisine, ou des sources archéologiques. Le spécialiste d'histoire de la médecine s'étonnera du fait que certains usages médicaux, et magiques, au sens propre, ne soient pas étudiés, alors qu'ils auraient parfaitement correspondu au titre du chapitre, «Pflanzen aus der Sicht ihrer magischen Verwendung ». C'est ainsi le cas des plantes qui étaient utilisées pour influer sur le sexe de l'enfant à naître. On regrettera surtout que les aspects culturels, à proprement parler, du sujet ne soient pas traités avec autant d'attention que les aspects économiques et médicaux, qui représentent plus d'un tiers de l'ouvrage. Ce n'est qu'avec les deux derniers chapitres que l'auteur tient véritablement la promesse de son sous-titre. Surtout, l'ouvrage pâtit de son absence de conclusion : se terminant de façon abrupte, il apparaît comme une succession de chapitres thématiques, et la vision d'ensemble peine à se dessiner.

\section{INDEX}

Index chronologique : Moyen Âge

Thèmes : Histoire de la culture, Histoire des mentalités 
AUTEUR

ADELINE REGE

Université de Strasbourg 